\title{
Maternal Mortality and Morbidity Will Not Reduce in Low Resource Countries without the Anaesthetists' Involvement
}

\author{
Elizabeth Ogboli-Nwasor \\ Department of Anaesthesia, Ahmadu Bello University Teaching Hospital, Zaria, Nigeria \\ Email: drnwasor@yahoo.com
}

Received 27 January 2014; revised 25 February 2014; accepted 5 March 2014

Copyright (C) 2014 by author and Scientific Research Publishing Inc.

This work is licensed under the Creative Commons Attribution International License (CC BY). http://creativecommons.org/licenses/by/4.0/

(c) (i) Open Access

\begin{abstract}
Background: Maternal and foetal mortality is unacceptably high in most resource-limited countries and the practice of obstetric anaesthesia has an important influence on outcome for both mother and baby. The much needed close co-operation and collaboration between obstetricians and obstetric anaesthetist providers is crucial for the safety and comfort of parturients, particularly in lowresource environments. The current global maternal mortality is approximately 400 per 100,000 deliveries, with a range of $7-740$ deaths per 100,000, demonstrating the inequality between the rich and poor countries. Many of the deaths could have been prevented by better essential obstetrics services including safe anaesthesia and surgery, provided such services are made available in a timely manner. Conclusion: Maternal mortality in low resource countries has its basis complex social, economic and political factors, underpinned by a lack of resources. Many of these factors are difficult and slow to resolve and are not specific to maternal health. Comprehensive essential obstetric care services at the district hospital level (first referral level) should include all the above plus safe surgery, safe anaesthesia, and blood transfusion. Government, donor agencies and all stakeholders must recognize the crucial role of anaesthesia in providing emergency obstetric care in hospitals. Advocacy by all concerned will help direct the scarce resources to the appropriate areas of need which includes provision of adequate facilities and manpower for safe anaesthesia.
\end{abstract}

\section{Keywords}

Obstetric Anaesthesia; Maternal Mortality; Low Resource

\section{Introduction}

The maternal mortality ratio (MMR) is the ratio of maternal deaths to live births, the lifetime risk of maternal

How to cite this paper: Ogboli-Nwasor, E. (2014) Maternal Mortality and Morbidity Will Not Reduce in Low Resource Countries without the Anaesthetists' Involvement. Open Journal of Obstetrics and Gynecology, 4, 228-233. 
death being the probability of maternal death during a woman's reproductive life. Official figures probably underestimate MMR as deaths due to childbirth may be wrongly attributed, denominator data are lacking and death registration systems poorly developed [1] in many low-resource countries. Even in countries where audits of maternal deaths are well developed, there is significant under-reporting [2].

Maternal death is defined according to the tenth revision of the International Classification of Diseases, Injuries and Causes of Death (ICD 10) as: "the death of a woman while pregnant or within 42 days of termination of pregnancy, from any cause related to or aggravated by the pregnancy or its management, but not from accidental or incidental causes” [3].

Maternal mortality rates of 630 deaths/100,000 live births (2010) have been recorded in various parts of Nigeria with the figures more than twice as high as in the rural areas [4].

Maternal mortality and morbidity will not reduce in low resource countries without anaesthesia involvement. Why am I putting forward this position?

This statement is based on the Millennium Development Goal 5 which is to "Improve maternal health and reduce maternal mortality by $75 \%$ between 1990 and 2015 ”.

Why do these mothers die?

Obstetric haemorrhage is the most common cause, causing 166,000 deaths per annum, with half of these in sub-Saharan Africa [5]. Hypertensive disorders, obstructed labour and infection, including post-abortion, are the other major causes of death, most of which are preventable [3] [6]. There is a strong relationship between maternal death and poverty: in Indonesia, 33\% of deaths occur among women from the poorest quintile of the population [7].

Is the fifth Millennium Development Goal achievable?

Yes it is. What are the strategies to achieve reduction in maternal mortality using anaesthesia as a baseline?

Reasons for declining maternal mortality:

1) Improvement in health systems.

2) Increased female education.

3) Increased physical accessibility.

MDG 5 indicators include:

1) The proportion of deliveries attended by skilled health personnel in developing regions rose from $55 \%$ in 1990 to $65 \%$ in 2009 [8].

2) The proportion of women who were attended to by skilled health-care personnel at least once during pregnancy increased from $64 \%$ to $81 \%$.

3) The proportion of women aged 15 - 49 years who use any method of contraception also increased from $52 \%$ to $61 \%$.

4) More recently, the rapid roll-out of antiretroviral therapy in sub-Saharan Africa to HIV-positive women, from $<10 \%$ in 2000 to $55 \%$ in 2010 , improves the chances of surviving the additional demands of pregnancy in immune-compromised health [9].

Improvement in the coverage of these health-care interventions over the past two decades may have contributed to improved outcomes in those countries that have recorded reduction in maternal mortality rates. Efforts to improve maternal health and reduce maternal deaths should be focused on addressing inequalities across and within countries.

\section{The Influence of Obstetric Anaesthesia on Maternal Mortality}

Anaesthetists are an integral part of the obstetric team and participate in the management of over $50 \%$ of parturients in a typical obstetric unit in the UK [10]. Many of these interventions are related to the provision of analgesia for normal labour, and provision of anaesthesia for high risk obstetrics such as obstetric haemorrhage, hypertensive disorders, obstructed labour and infection, including post-abortion, and the other major causes of death, most of which are preventable. Provision of most of these obstetric anaesthesia services are out of the reach of the majority in the developing world.

1) Anaesthetists have knowledge of acute physiology and are adept at fluid management, invasive monitoring and other aspects of intensive care. They are an integral part of the team managing obstetric complications, including the critically ill mother with obstetric haemorrhage, sepsis or eclampsia.

2) Anaesthetists provide safe anaesthesia for high risk obstetrics,

3) Manage the airway, 
4) Perform effective resuscitation,

5) Assess and manage critically ill mothers in the intensive care unit,

6) Assist with neonatal resuscitation and

7) Offer effective pain relief during and after childbirth.

These services, are sometimes lacking in low resource countries, BECAUSE there are VERY FEW OR NO anaesthetists to provide them!

Many mothers need more than basic obstetric care [11]. In the developing world, many women present to secondary institutions with life-threatening complications; additional lives could be saved if the anaesthetic provider was skilled at recognizing the need for, and was able to carry out, prompt and effective resuscitation. The anaesthetic provider should play a leading role in the provision of basic intensive care. It is likely that the lack of trained anaesthesia personnel is a limiting factor in the provision of care for the critically ill mother in developing countries [12].

There is a growing body of evidence to suggest that basic obstetric treatment is cost-effective, and further evidence suggests that the presence of trained anaesthetists improves outcomes [13] [14].

Essential obstetric care is the term used to describe the elements of obstetric care needed for the management of normal and complicated pregnancy, delivery and the postpartum period.

Essential Obstetric Care is defined for two different levels of the health care system:

Basic essential obstetric care services at the health centre level should include at least the following:

1) Parenteral antibiotics.

2) Parenteral oxytocic drugs.

3) Parenteral sedatives for eclampsia.

4) Manual removal of placenta.

5) Manual removal of retained products.

Comprehensive essential obstetric care services at the district hospital level (first referral level) should include all the above plus

1) Surgery,

2) Anaesthesia, and

3) Blood transfusion.

For the services at a facility to be considered functional, all the above elements of care must have been provided during the 6 months previous to data collection [15].

Thus anaesthesia is part of provision of comprehensive essential obstetric care services. Anaesthesia is required for caesarean section. Although the WHO recommends a caesarean section rate of between 5\% and 10\%, in reality caesarean section rates are below 1\% for the poorest populations in 20 countries, most of them in subSaharan Africa [16]. This is in part due to a lack of anaesthesia provision, particularly in rural areas. In India, whereas $70 \%$ of district hospitals have a medically qualified anaesthetist, only $22 \%$ of the rural hospitals have an anaesthetist. Anaesthesia is included in the undergraduate curriculum in India, but medical officers are discouraged from practising anaesthesia. Government policies do not encourage doctors to train as anaesthetists-there are few training positions, remuneration and working conditions are poor, and most doctors prefer to work in private practice in urban areas or migrate [5]. Medical migration in sub-Saharan Africa means that medically qualified anaesthetists are a rarity, and the majority of anaesthesia is administered by anaesthetic officers with up to 1 - 3 years training, but even then, they are few in number compared to the population size [17]. See also Table 1.

\section{The Solutions}

Innovative strategies have been suggested to address this shortage of anaesthetists, particularly in rural areas. For instance, in some parts of rural India, obstetricians initially give anaesthesia, which is then maintained by a medical officer or nurse. This practice is however not advisable as it will not encourage the training of anaesthetists. Some obstetricians perform caesarean section under local anaesthesia [5]. These strategies alone however may not be associated with improved maternal outcomes and so should be discouraged.

Non-medical anaesthesia providers have been trained in Bangladesh for several years and are being trained in Nepal. Where no anaesthesia provision exists in remote areas, mortality is likely to be lower when trained personnel are provided, although aspects of their training, working facilities and supervision may be less than ideal [5]. In most of sub-Saharan Africa, medical anaesthetists are only found in larger urban hospitals and a vast majority of anaesthetics are administered by non-physician anaesthetic providers working alone, unsupervised, and 
Table 1. Statistics of physician anaesthetists in some countries in Africa (2012).

\begin{tabular}{cccc}
\hline Country & Population $(\mathrm{M})$ & Anaesthetists & Anaesth/population (M) \\
\hline Benin & 10 & 20 & $1 / 0.5$ \\
Burkina F. & 16 & 16 & $1 / 1$ \\
Cameroon & 20 & 30 & $1 / 0.6$ \\
Eritrea & 5.6 & 0 & 0 \\
Ethiopia & 76 & 12 & $1 / 6.2$ \\
Ivory Coast & 21 & 98 & $1 / 0.2$ \\
Ghana & 18 & 50 & $1 / 0.4$ \\
Guinea & 10 & 06 & $1 / 0.6$ \\
Guinea-Bissau & 1.6 & 4 & $1 / 0.4$ \\
Mali & 14 & 13 & $1 / 1$ \\
Central Africa & 05 & 00 & 00 \\
Togo & 06 & 5 & $1 / 1.2$ \\
Tchad & 10 & 02 & $1 / 5 \mathrm{M}$ \\
Nigeria & 170 & 400 & $1 / 0.4 \mathrm{M}$ \\
Niger & 17 & 11 & $1 / 1.5$ \\
Malawi & 16 & 3 & $1 / 5.3$ \\
South Africa & 51.2 & 800 & $1 / 0.06$ \\
\hline
\end{tabular}

often with limited training. This is simply not acceptable and may compromise patient safety and lead to unnecessary deaths. With the current social and economic constraints, this situation is unlikely to change and unless the focus and emphasis is placed on should be on improving the numbers, training and skills of medical anaesthesia providers.

The importance of training is clear when considering outcomes from surgery. Emergency caesarean section is the commonest major surgical procedure in Africa [18]. There have been a few reports which indicate that the peri-operative mortality is extremely high, estimated as high as $1 \%-2 \%$ [19]-[23]. Most of these deaths are avoidable and one-third of deaths are directly attributable to anaesthesia, mainly due to airway problems. Another significant cause is access to blood for transfusion. A publication from Togo in 2003, showed that there were 12 deaths associated with anaesthesia for 318 cases over a 6-month period [24]. The aim of that study was to assess the results of anaesthesia practices in a department particularly inadequately staffed with physicians specializing in anaesthesiology. The majority of the 306 Caesarean sections involved were performed under general anaesthesia. Intraoperative monitoring was essentially nonexistent. Emergency situations accounted for $89.6 \%$ of these surgical procedures. The principal causes of death were respiratory complications of anaesthesia and of pregnancy-related toxaemia and the unavailability of hypertonic solutions and blood products. There were three cases of aspiration, one unrecognised oesophageal intubation, one pulmonary oedema and one postoperative hypoxia resulting from inadequate reversal. However, there has been a marked increase in the use of spinal anaesthesia since this article was written.

Previous reports have suggested lack of anaesthesia provision as a contributing factor in a large number of cases, most deaths occurring in the rural areas which have limited availability of trained anaesthetists [25]. The AAGBI recommends minimal standards during anaesthesia, including the availability of monitors-ECG, pulse oximeter and capnography. Only 6\% of anaesthetists in Uganda had even the most basic facilities to deliver safe anaesthesia for obstetric anaesthesia (spinal needles, blood for transfusion, oxytocic agents, antihypertensive agents or magnesium sulphate), let alone anaesthesia monitors [17]. This lack of facilities makes a significant contribution to high peri-operative maternal mortality. The conclusion is that while spinal anaesthesia may be safer than general anaesthesia, it still requires a skilled and careful practitioner with appropriate facilities for its inherent safety to be realized.

Thus concerted efforts should be made by all the responsible agencies to train physician anaesthetists in the low resource areas of Africa. Table 2 shows the trends in manpower development in the training of physician 
Table 2. Trends in man power development.

\begin{tabular}{ccccc}
\hline Country & 1984 & 1990 & 2002 & 2012 \\
\hline Benin & 02 & 04 & 09 & 20 \\
Burkinafaso & 01 & 02 & 06 & $400+$ \\
Nigeria & 10 & 20 & 100 & 98 \\
Ivory Coast & 12 & 32 & 50 & 13 \\
Mali & 01 & 06 & 10 & 30 \\
Cameroun & 04 & 12 & 20 & 35 \\
Senegal & 04 & 14 & 28 & 11 \\
Niger & 01 & 03 & 05 & 243 \\
Total & 09 & 70 & 123 & \\
\hline
\end{tabular}

anaesthetists in some countries in the West African sub-region over the past two to three decades. These figures are appalling and grossly inadequate when compared to the figures from other subspecialties that anaesthesia provides routine services to such as obstetrics and gynaecology, general surgery, urology, paediatric surgery and ENT to name but a few.

Mothers die as a result of poorly functioning healthcare systems, particularly in rural areas. Families may be slow to recognize and seek help for complications of pregnancy, birth attendants are untrained, access to healthcare is hindered by poor transport, and high cost of healthcare may be an additional barrier because of poverty [1]. Once secondary health care is accessed, the facilities may be inadequate at all levels (district and referral), particularly access to skilled practitioners, equipment, drugs and blood for transfusion. There are cumulative delays at every stage, and even if the mother survives, the outcomes for baby are dire-neonatal deaths far outweigh maternal deaths (4 million annually), and are inextricably linked to inadequate perinatal care [25].

\section{Conclusions}

Maternal mortality in low resource countries has its basis complex social, economic and political factors, underpinned by a lack of resources. These factors are difficult and slow to resolve and are not specific to maternal health.

There are no simple solutions, therefore interventions are required at every level, including community level (trained birth attendants, access to antibiotics, injectable oxytocics and oral misoprostol). Comprehensive essential obstetric care services at the district hospital level (first referral level) should include all the above plus safe surgery, safe anaesthesia, and blood transfusion. However, since many mothers die in hospital; it is crucial that resources are directed at health centres and hospitals as well as community programmes. A lack of trained staff including anaesthetists, essential medicines and equipment is the most significant barriers to improved healthcare.

Government, donor agencies and all stakeholders must recognize the crucial role of anaesthesia in providing emergency obstetric care in hospitals. Advocacy by all concerned will help direct the scarce resources to the appropriate areas of need. There needs to be serious commitment to train and provide on-going supervision for adequate numbers of anaesthesia providers who have the appropriate facilities and equipment with reliable access to supplies of drugs. Only then will in-hospital maternal mortality rates fall.

\section{References}

[1] Sombie, I., Meda, N. and Ky-Serbo, O. (2005) Maternal Mortality in Rural Burkina Faso. British Medical Journal, 331, 779. http://dx.doi.org/10.1136/bmj.331.7519.779

[2] Graham, W. and Hussein, J. (2004) The Right to Count. Lancet, 363, 67-68. http://dx.doi.org/10.1016/S0140-6736(03)15174-4

[3] Centre for Maternal and Child Enquiries (CMACE) (2011) Saving Mothers' Lives: Reviewing Maternal Deaths to Make Motherhood Safer: 2006-08. The Eighth Report on Confidential Enquiries into Maternal Deaths in the United Kingdom. BJOG, 118, 1-203. 
[4] Maternal Mortality (2006) World Health Organization Fifty-Ninth World Health Assembly A 59/9. Provisional Agenda Item 11.4. http://www.indexmundi.com/nigeria/maternal_mortality_rate.html

[5] Mavalankar, D.V. and Rosenfield, A. (2005) Maternal Mortality in Resource-Poor Settings: Policy Barriers to Care. American Journal of Public Health, 95, 200-203. http://dx.doi.org/10.2105/AJPH.2003.036715

[6] Begum, S., Aziz, N. and Begum, I. (2003) Analysis of Maternal Mortality in a Tertiary Care Hospital to Determine Causes and Preventable Factors. Journal of Ayub Medical College Abbottabad, 15, 49-52.

[7] Graham, W.J., Fitzmaurice, A.E., Bell, J.S., et al. (2004) The Familial Technique for Linking Maternal Death with Poverty. Lancet, 363, 23-27. http://dx.doi.org/10.1016/S0140-6736(03)15165-3

[8] (2011) The Millennium Development Goals Report 2011. New York, United Nations. http://mdgs.un.org/.../Progress2011/11-31339\%20(E)\%20MDG\%20Report\%2

[9] WHO, UNICEF and UNAIDS (2011) Global HIV/AIDS Response: Epidemic Update and Health Sector Progress towards Universal Access Progress Report 2011. World Health Organization, Geneva. http://whqlibdoc.who.int/publications/2011/9789241502986_eng.pdf

[10] The Association of Anaesthetists of Great Britain and Ireland (1998) The Obstetric Anaesthetists Association. Guidelines for Obstetric Anaesthesia Services. AAGBI, OAA, London.

[11] Costello, A., Azad, K. and Barnett, S. (2006) An Alternative Strategy to Reduce Maternal Mortality. Lancet, 368, 1477-1479. http://dx.doi.org/10.1016/S0140-6736(06)69388-4

[12] Clyburn, P., Morris, S. and Hall, J. (2007) Anaesthesia and Safe Motherhood. Anaesthesia, 62, 21-25. http://dx.doi.org/10.1111/j.1365-2044.2007.05293.x

[13] Kushner, A., Cherian, M.N., Noel, L., Spiegel, D.A., Groth, S., et al. (2010) Addressing the Millennium Development Goals from a Surgical Perspective. Essential Surgery and Anaesthesia in 8 Low- and Middle-Income Countries. Archives of Surgery, 145, 154-159. http://dx.doi.org/10.1001/archsurg.2009.263

[14] Debas, H.T., Gosselin, R., McCord, C., et al. (2006) Surgery. In: Jamison, D.T., Breman, J.G., Measham, A.R., et al., Eds., Disease Control Priorities in Developing Countries, 2nd Edition, Oxford University Press, New York, 12451260.

[15] (2013) Essential Obstetric Care. World Health Organization Fact Sheet No. 245. http://www.who.int/mediacentre/factsheets/fs245/en/

[16] Ronsmans, C., Holtz, S. and Stanton, C. (2006) Socioeconomic Differentials in Caesarean Rates in Developing Countries: A Retrospective Analysis. Lancet, 368, 1516-1523. http://dx.doi.org/10.1016/S0140-6736(06)69639-6

[17] Hodges, S.C., Mijumbi, C., Okello, M., McCormick, B.A., Walker, I.A. and Wilson, I.H. (2007) Anaesthesia Services in Developing Countries: Defining the Problems. Anaesthesia, 62, 4-11. http://dx.doi.org/10.1111/j.1365-2044.2006.04907.x

[18] Nordberg, E. (1990) Surgical Operations in Eastern Africa: A Review with Conclusions Regarding the Need for Further Research. East African Medical Journal, 67, 1-28.

[19] Heywood, A.J., Wilson, I.H. and Sinclair, J.R. (1989) Perioperative Mortality in Zambia. Annals of the Royal College of Surgeons (England), 71, 354-358.

[20] Hansen, D. and Gausi, S.C. (2000) Anaesthesia in Malawi: Complications and Deaths. Tropical Doctor, 30, $146-149$.

[21] Fenton, P.F., Whitty, C.J.W. and Reynolds, F. (2003) Caesarean Section in Malawi: Prospective Study of Maternal and Perinatal Mortality. British Medical Journal, 327, 587-590. http://dx.doi.org/10.1136/bmj.327.7415.587

[22] McKenzie, A.G. (1998) Operative Mortality at Harare Central Hospital 1992-94: An Anaesthetic View. International Journal of Obstetric Anesthesia, 7, 237-241. http://dx.doi.org/10.1016/S0959-289X(98)80045-9

[23] Tomta, K., Ouro-Bang’na Maman, A.F., Ahouaangbevi, S. and Chobli, M. (2005) Deaths Associated with Anaesthesia in Togo, West Africa. Tropical Doctor, 35, 220-222. http://dx.doi.org/10.1258/004947505774938666

[24] Tomta, K., Maman, F.O., Agbétra, N., Baeta, S., Ahouangbévi, S. and Chobli, M. (2003) Mortalité Maternelle: Implication Anesthésique au CHU de Lomé (Togo). Sante, 13, 77-80.

[25] Lawn, J.E., Tinker, A., Munjanja, S.P. and Cousens, S. (2006) Where Is Maternal and Child Health Now? Lancet, 368, 1474-1477. http://dx.doi.org/10.1016/S0140-6736(06)69387-2 